\title{
K-pop, ativismo de fã e desobediência epistêmica: um olhar decolonial sobre os ARMYs do BTS
}

\author{
K-pop, fan activism and epistemic disobedience: \\ a decolonial glance at BTS's ARMYs
}

KRYSTAL URBANO

Universidade Federal Fluminense Doutora e Mestre em Comunicação pela Universidade Federal Fluminense (PPGCOM | UFF). Jornalista e Especialista em Epistemologias do Sul (CLACSO | Argentina). Coordenadora Adjunta do MidiÁsia (Grupo de Pesquisa em Mídia e Cultura Asiática Contemporânea - PPGCOM | UFF). https://orcid.org/0000-00020918-8383

krystal.cortez@gmail.com

DANIELA MAZUR

Universidade Federal Fluminense Doutoranda pelo Programa de PósGraduação em Comunicação da Universidade Federal Fluminense (PPGCOM-UFF). Pesquisadora vinculada ao MidiÁsia (Grupo de Pesquisa em Mídia e Cultura Asiática Contemporânea PPGCOM | UFF). https://orcid.org/0000-00018869-9159

danielamazur@id.uff.br

\section{MAYARA ARAUJO}

Universidade Federal Fluminense Doutoranda pelo Programa de PósGraduação em Comunicação da Universidade Federal Fluminense (PPGCOM-UFF). Pesquisadora vinculada ao MidiÁsia (Grupo de Pesquisa em Mídia e Cultura Asiática Contemporânea PPGCOM | UFF). https://orcid.org/0000-00032548-5051 msoareslpa@yahoo.com.br

\section{AFONSO DE ALBUQUERQUE}

Universidade Federal Fluminense Professor titular da Universidade Federal Fluminense (UFF). Doutor em Comunicação pela Universidade Federal do Rio de Janeiro. Coordenador geral do MidiÁsia (Grupo de Pesquisa em Mídia e Cultura Asiática Contemporânea PPGCOM | UFF). https://orcid.org/0000-00022608-7605 afonsoal@uol.com.br 


\section{RESUMO}

Os fãs de K-pop têm chamado a atenção da mídia internacional por conta de seu engajamento em causas políticas e sociais em diversos países. No intuito de investigar a dimensão política do ativismo desses fãs em específico, este artigo se propõe a abordar o impacto global do K-pop, tendo em vista o debate mais abrangente sobre decolonialidade. Para tanto, utilizamos como objeto de análise o recente caso do fã-clube oficial do BTS, conhecido como ARMY, que desafiou os posicionamentos do presidente norte-americano Donald Trump. A partir de uma abordagem decolonial e da concepção de desobediência epistêmica, apontamos que o consumo da cultura pop sul-coreana dispõe de ferramentas que dialogam com a esfera não-ocidental e funciona fora da lógica colonial, especialmente em meio a ascensão global da boyband BTS.

Palavras chave: Decolonização; Ativismo de fãs; K-pop.

\section{ABSTRACT}

$K$-pop fans have been attracting the attention of the international media due to their engagement in political and social causes in several countries. In order to investigate the political dimension of these fans' activism in particular, this article proposes to address the global impact of K-pop, in view of the broader debate on decoloniality. To do so, we used as an object of analysis the recent case of the official BTS fan club, known as ARMY, which challenged the positions of US President Donald Trump. From a decolonial approach and the concept of epistemic disobedience, we point out that the consumption of South Korean pop culture has tools that dialogue with the non-Western sphere and works outside colonial logic, especially in the midst of the global rise of the boyband BTS.

Keywords: Decolonization; Fan's activism; K-pop. 


\section{INTRODUÇÃO}

No dia 21 de junho de 2020, os fãs transnacionais (MORIMOTO; CHIN, 2013) de K-pop chamaram a atenção do mundo com uma ação política inusitada. Em uma ação coordenada, eles reservaram milhares de ingressos para um evento de apoio a Donald Trump, candidato à reeleição ao posto de presidente dos Estados Unidos com a intenção de faltarem e esvaziar o evento. A reação não se fez por esperar. Furiosas, as lideranças republicanas acusaram os k-poppers de integrarem um movimento conspiratório anti-estadunidense mais amplo, conectado à China, a grande nêmesis do universo político trumpista. Afinal, o que haveria por detrás da superfície do K-pop que explicaria tal mobilização? Nos dias que se seguiram, a cobertura das empresas jornalísticas ao redor do mundo foi tomada por matérias ${ }^{[1]}$ que buscavam respostas para o fenômeno. "Seria o K-pop o novo punk?"[2], indagavam algumas delas.

As diferenças entre o punk e o K-pop são imensas: de um lado, um movimento com características antissistema, revolta contra o princípio da autoridade e forjado no ambiente proletário das sociedades ocidentais; do outro, um movimento cultural cunhado com base nas convenções mais gerais do pop - um gênero musical abertamente comercial (FRITH, 1996) e relido à luz dos parâmetros de disciplina e moralidade da Coreia do Sul, que se tornou um fenômeno global há mais de uma década. O que emprestaria a esse movimento um caráter tão contestador? A fim de responder a essa questão, esse artigo se propõe a investigar o impacto político do K-pop tendo em vista o debate mais abrangente sobre o decolonial (MIGNOLO, 2005; QUIJANO, 2007). Para tal, é preciso focar menos na mensagem das bandas do que no circuito que deu ao K-pop impacto mundial. Em outras palavras, o que torna o fenômeno do K-pop incômodo é menos uma questão de "o que" - um discurso "subversivo" que ele enunciaria - do que de "quem": o fato de que sociedades situadas para além do escopo do chamado Ocidente tenham se tornado capazes de fornecer modelos atraentes em termos globais.

A ansiedade dos setores conservadores estadunidenses frente ao K-Pop assume um caráter de pânico moral, que deriva da percepção do declínio da capacidade do país em exercer soft power $^{[3]}$ (NYE, 2005) em escala global, de maneira quase monopolística, como acontecera desde o fim da década de 1990. A Coreia do Sul não é, contudo, o único alvo desse pânico; ele atinge também (e ainda mais intensamente) a China, cujas empresas de comunicação recentemente se tornaram competidores globais capazes de ameaçar a liderança das empresas estadunidenses. Por este motivo empresas como a Huawei e TikTok se tornaram alvos de retaliação por parte do governo dos Estados Unidos, que buscam compensar por meio de sanções políticas, a incapacidade de suas empresas de concorrer com elas em termos de mercado. A pandemia do COVID-19 acrescentou novos elementos à trama, uma vez que a sua caracterização como um 
"vírus chinês" deu origem a uma retomada da grande narrativa do "perigo amarelo", culminando na emergência do discurso orientalista vinculado aos países do Extremo Oriente profundamente sentido nas narrativas midiáticas (URBANO; ARAUJO; MELO, 2020).

A emergência do K-pop e as dinâmicas políticas a ele associadas permitem debater o decolonial a partir de um ângulo pouco explorado. O debate decolonial clássico dá conta dos desafios enfrentados por sociedades situadas para além do mundo ocidental de positivarem seus valores e práticas - e em termos mais amplos, o seu lugar de fala - na sociedade globalizada, em um contexto em que - por obra e graça do imperialismo - as sociedades ocidentais se tornaram capazes de reivindicar para si a capacidade de exprimir valores humanos "universais". A reação negativa ao K-pop e outros produtos culturais emergentes das sociedades do Extremo Oriente, contudo, diz respeito a algo bem diferente: a reação ao risco de perda do monopólio do lugar do "universal" pelo Ocidente, em face da ascensão de competidores de outras partes do mundo.

A crítica decolonial pode nos oferecer um ponto de vista promissor na compreensão do fenômeno do k-pop e seu impacto político no mundo global. Mais do que isso: nos permite pensar o fenômeno não só enquanto um exemplar de estética decolonial (MIGNOLO; VÁSQUEZ, 2013) mas também enquanto prática política atrelada a ele. De fato, os fãs de k-pop - a exemplo do caso estadunidense - vem adotando diversas estratégias de engajamento, resistência e de produção de conhecimento contra-hegemônicas, que se relaciona intimamente com a noção de "desobediência epistêmica" (MIGNOLO, 2008). Tal desobediência se manifesta de maneira mais contundente quando observamos que esses fãs vêm se engajando maciçamente nos protestos contra o racismo anti-negro que começaram nos EUA e se espalharam pelo mundo. Ao contribuírem ativamente para evitar a disseminação nas redes sociais de posts racistas e de denúncias de ativistas à polícia, esses fãs demonstram a relação intrínseca entre suas estéticas, práticas e visões de mundo não-ocidentais com o movimento Black Lives Matter e seus protagonistas, o que requer maiores investigações.

A fim de lançar um olhar decolonial em torno do k-pop e suas dinâmicas políticas-identitárias associadas, o artigo se divide em três partes. Na primeira, apresentamos o debate mais amplo sobre o decolonial do ponto de vista do fenômeno do pop, apontando as colonialidades presentes em termos de sua estética e práticas, bem como as decolonialidades possíveis derivadas dele. Na segunda, abordamos o fenômeno da Onda Coreana (Hallyu) e o papel do K-pop na ascensão da Coreia do Sul como um polo em ascensão de produção de cultura pop reconhecido no cenário internacional. E, por fim, na terceira seção analisamos o fã-clube da boyband BTS (Bangtan Boys) - o ARMY -, apontando para as raízes decoloniais e de natureza de desobediência epistêmica existente no comportamento desses fãs, e também do próprio levante sul-coreano em meio a lógica "global" do pop. 


\section{O POP COMO ESTÉTICA E PRÁTICA À LUZ DO DECOLONIAL}

Os estudos sobre o decolonial constituem nosso ponto de partida para refletir sobre um mundo culturalmente diversificado e multipolarizado. Em um momento no qual a permanência da "colonialidade do poder" vem sendo desafiada em várias instâncias da vida social, relacionamos a análise aos estudos de Quijano (2007) e Mignolo (2005, 2017) que entendem o termo como as várias dimensões de poder constitutivas do colonialismo e de seus legados. Mignolo (2005) argumenta que a modernidade-colonialidade ativa uma estrutura de saberes concebidos e utilizados para promover a naturalização de específicas visões de mundo, saberes e técnicas, assim mantidos como hegemônicas. A colonialidade seria "a lógica subjacente da fundação e do desdobramento da civilização ocidental desde o Renascimento até hoje, da qual colonialismos históricos têm sido uma dimensão constituinte, embora minimizada" (MIGNOLO, 2017, p. 2). Por sua vez, Quijano (2007) distingue os termos "colonialismo" e "colonialidade", quando sugere que as relações de colonialidade não findaram com o término do colonialismo. Com isso, a proposta "decolonial" se distingue também do termo "descolonização", que se refere ao processo histórico de libertação nacional durante a Guerra Fria (MIGNOLO, 2008b).

A crítica decolonial resgata cosmovisões invisibilizadas como resultado do apagamento imperialista. Por isso, ao analisarmos o pop enquanto estética e prática à luz do decolonial, emergem dois cenários distintos. O primeiro se refere às lógicas coloniais, com a imposição de imagens, sonoridades, idiomas e/ou repertórios estéticos eurocêntricos, acompanhado de práticas sociais e midiatizadas que corroboram com o apagamento imperialista da pluralidade de cosmovisões. O outro diz respeito a um modelo de estética e prática decolonial que representa outras cosmovisões, geralmente não-ocidentais e não-anglófonas, enquanto um exemplar de resistência e reação ao repertório estético mainstream, isto é, enquanto uma prática efetiva de "desobediência epistêmica" e proposta de produção de conhecimento contra-hegemônico atrelada ao pop e seus públicos. Ambas acepções estão imbricadas, sendo que a possibilidade da segunda necessita da constatação e compreensão da primeira.

Historicamente, tanto a estética do pop quanto as práticas e reflexões sobre esse fenômeno estiveram fortemente ancoradas a um legado estadunidense e, em menor escala, britânico (ALBUQUERQUE; CORTEZ, 2015). A partir da década de 1980, o pop passou a ser considerado como um sinônimo de homogeneização cultural, conduzido a partir de uma perspectiva necessariamente ocidental. Tal constatação pode ser observada através dos grandes "ícones" do pop e, em especial, do espectro da música, que receberam bastante visibilidade midiática no decorrer do tempo: Michael Jackson, Madonna, Justin Bieber, Lady Gaga e Miley Cyrus são nomes frequentemente evocados ao se refletir sobre o assunto. Não obstante, pesquisas acadêmicas na 
área da Comunicação também tendem a privilegiar investigações acerca da cultura pop à luz de referenciais téoricos e objetos de estudos empíricos ocidentais (SOARES, 2014; BENNET, 2014).

A construção do Ocidente como uma categoria "universal", que empurra a sua realidade particular para o resto do mundo, nos ajuda a compreender essa situação. A agenda do universalismo reforça o pressuposto da superioridade ocidental sobre os "outros" (países que não fazem parte do eixo central), através de uma política apresentada como parte dos valores e verdades universais, que não seriam comungados por países não-ocidentais (WALLERSTEIN, 2007). O projeto político denominado "Ocidente", representando principalmente pelos países industrializados Europa, teve início no Iluminismo e definiu as bases e parâmetros que desenham o curso da História a partir de uma perspectiva centrada em si mesmos (GLUCK, 2018), apagando e abafando as Histórias dos "outros". Um processo descrito por Edward Said (2007) como o "estilo ocidental para dominar, reestruturar e ter autoridade sobre o Oriente" (SAID, 2007, p. 29). Mais recentemente a ocidentalidade anglófona tem ilustrado a primazia do mundo ocidental, liderado pelos Estados Unidos. Na medida em que o inglês reivindica para si uma "sonoridade universal", representantes do pop nativo de países anglófonos obtém um espaço diferenciado nessas dinâmicas desiguais que regem a lógica estrutural da indústria do pop mundial. Entretanto, o que o fenômeno da Hallyu representada pela música k-pop tem nos demonstrado é que tais estruturas já não são tão consolidadas conforme foram no passado.

Desde a virada do milênio, a quantidade de músicas não-anglófonas e a presença de artistas não-americanos de sucesso nos charts da Billboard - considerada a principal parada musical no mundo da música - se tornou mais comum, o que chamou a atenção do jornal britânico The Guardian, que em 2018 afirmou que "o inglês não é mais o idioma padrão do pop americano" ${ }^{[4]}$, dado o tamanho do destaque que estilos musicais como o K-pop e o Reggaeton tem conquistado internacionalmente. De fato, o BTS fez história com Love Yourself: Tear, ao colocar pela primeira vez um álbum cantado completamente em coreano em primeiro lugar nas paradas da Billboard. Não se trata de um caso pontual: as indústrias midiáticas do Leste Asiático têm se tornado cada vez mais expressivas e se apresentam, portanto, como uma alternativa às ideias consolidadas do pop ocidental: seja com o cinema de arte-marciais de Hong Kong na década de 1970, às séries animadas japonesas nos anos 1990 e, mais recentemente, com o K-pop da Coreia do Sul (URBANO, 2018).

A boyband sul-coreana BTS tem chamado a atenção pela expressiva quantidade de prêmios acumulados e, principalmente, pela movimentação de seus fãs cativos, altamente engajados e organizados. Assim, o grupo se tornou um verdadeiro fenômeno do pop e o seu fã-clube oficial, ARMYs $^{[5]}$ - sigla para Adorable Representative MC for Youth - são tão devotados que costumam compará-los com os fãs dos Beatles no século XX. O engajamento do fã-clube chamou a atenção 
da mídia internacional por conta de suas iniciativas relacionadas a questões políticas e causas sociais, como ilustra o recente caso envolvendo o atual presidente dos Estados Unidos, Donald Trump, conforme abordaremos mais à frente. O chamado "ativismo de fã" já teve bastante visibilidade midiática em outras oportunidades de levantes políticos e sociais (AMARAL; SOUZA; MONTEIRO, 2015; CHANG; PARK, 2019), como a constante utilização de símbolos da cultura pop nos protestos que ocorreram mundialmente no dia internacional das mulheres ${ }^{[6]}$ ou até com a emergência de uma "Brigada Otaku anti-fascista", encabeçada pelos fãs de desenhos animados japoneses que emergiu nos protestos do Chile no mesmo ano ${ }^{[7]}$. Interessa-nos, portanto, destacar a particularidade de um movimento contra-hegemônico que floresce no bojo do K-pop, reforçando mais uma vez a possibilidade de declínio da hegemonia norte-americana não somente no âmbito da cultura pop, mas também enquanto motor de influência política.

$O$ ativismo dos ARMYs pode ser compreendido como uma prática de resistência, ainda que não se apresente uma perspectiva que busca "romper com o sistema" (como nas premissas centrais do movimento punk, por exemplo). No entanto, acreditamos que o ativismo dos ARMYs rompe com a ideia de "pop" meramente vinculada aos cânones estéticos (e éticos) do mundo ocidental, que, portanto, se atentam e validam indústrias culturais para além do "eixo central" do mundo. Nesse sentido, os ARMYs colaboraram para impulsionar o movimento da Hallyu para além do aspecto regional do contexto do Extremo Oriente e deliberadamente têm questionado as políticas e posições estadunidenses no espectro global.

\section{HALLYU E O ADVENTO DO K-POP NA ARENA GLOBAL}

Em agosto de 2020, o grupo de k-pop BTS se tornou a primeira boyband sul-coreana a figurar em primeiro lugar na disputada lista estadunidense de músicas, a Billboard Hot $100^{[8]}$, com o single Dynamite. O primeiro lugar representa um efeito econômico de 7,5 bilhões de reais para a Coreia do $\mathrm{Sul}^{[9]} \mathrm{e}$, mais do que isso, aponta para o momento de virada que o mercado da música pop está vivenciando em meio a arena global. A ascensão do BTS como atual força pulsante da Hallyu apresenta não só o potencial do grupo, mas também o lugar da Coreia do Sul como um polo de produção de cultura pop que desafia a premissa da hegemonia e universalidade cultural estadunidense (MAZUR; MEIMARIDIS; ALBUQUERQUE, 2019). Tais conquistas resultam de um esforço de raiz industrial, governamental e cultural de um fenômeno conhecido como Hallyu, que tem no K-pop um de seus pilares mais importantes. 
O clipe Gangnam Style do sul-coreano Psy, manteve o posto de vídeo mais assistido do Youtube por 5 anos e ficou marcado na história da plataforma por "quebrar" o contador de visualizações em 2014 ao bater todos os recordes inimagináveis da época (JUNG; LI, 2014). A Hallyu é o fenômeno cultural de caráter transnacional originário da Coreia do Sul (SHIM, 2006; JIN; YOON, 2014), que se desenvolveu durante a década de 1990 e abarca o fluxo de produtos (programas televisivos, música, cinema, gastronomia, estética, literatura, idioma, turismo e celebridades) e influências nacionais que estão conquistando o cenário global (SHIM, 2006). Em 1997, ele tomou status de fenômeno cultural de exportação, inicialmente na China. A difusão midiática da cultura pop sul-coreana direcionou o interesse dos públicos internacionais para diferentes vertentes da cultura da Coreia do Sul, como gastronomia, literatura, estética e o próprio idioma (JIN; YOON, 2017).

A Hallyu e a ascensão da Coreia do Sul como um polo de influência cultural na região se apresentam ao final de um século de grandes reviravoltas e intervenções estrangeiras na península coreana. De 1910 a 1945, o Japão invadiu e colonizou o que, à época, era chamado de Império Coreano, território hoje dividido entre Coreia do Norte e Coreia do Sul (HWANG, 2010). A expansão imperialista japonesa foi violenta, instituindo domínio local, além de explorar recursos naturais, violentar colonos e impor restrições contra a cultura e identidade coreana. Um dos destaques dos horrores desse período continua em voga na mídia, as "mulheres de conforto", coreanas que foram forçadas a escravidão sexual pelo exército japonês. Com a participação e fracasso do Japão na Segunda Guerra Mundial, em 1945 os Estados Unidos e a União Soviética se apossaram e dividiram a colônia japonesa, estadunidenses ao sul do território peninsular e os soviéticos ao norte, sistemas políticos diferentes. O levante da Guerra Fria desencadeou a Guerra da Coreia em 1950, com apoio e intervenção diretos dos Estados Unidos e União Soviética. Após três anos de embate aconteceu o cessar-fogo, contudo a Guerra da Coreia continua ativa, sem um acordo de paz. Logo em seguida, durante as décadas de 1960 e 1980, o país foi marcado por uma intensa ditadura militar que, com influência norte-americana, apostou em planos capitalistas de desenvolvimento nacional. Foi apenas com o processo de democratização nacional que o fenômeno Hallyu se formou em meio a periferia global, apresentando um plot-twist pós imperialismo japonês e ocupação estadunidense no país. Ainda assim, embora a Coreia do Sul seja uma nação independente, os Estados Unidos continuam inferindo influências ao país até a atualidade, além de haver a presença de militares estadunidenses no território sul-coreano em razão da guerra que continua em vigor, mesmo que sem confrontos.

Atualmente, a Hallyu veicula não só produtos, mas um estilo de vida atrelado a eles (MAZUR, 2018). Sua indústria cultural se tornou um meio de expansão econômica para o país e também uma fonte atualizada da identidade nacional, elevando o status da Coreia do Sul na Ásia 
(HUANG, 2011), recapturando o imaginário cultural do leste-asiático e redirecionando a produção midiática regional (KEANE; FUNG; MORAN, 2007). A Coreia do Sul é hoje a décima segunda maior economia do mundo e graças à Hallyu, os lucros de exportação de produtos midiáticos e culturais ultrapassaram em 2019 a marca dos 10 bilhões de dólares e, em 2020, o governo nacional designou 1,42 bilhão de dólares em estímulos para o desenvolvimento de conteúdo cultural local ${ }^{[10]}$ em favor de manter o crescimento dessa influência pelo mundo.

O primeiro momento da Onda Coreana foi liderado pelos dramas de TV, que introduziram através das suas narrativas outras vertentes do movimento, especialmente o K-pop pelas suas trilhas sonoras. Nessa época, a Hallyu tinha caráter estritamente regional, alcançando especialmente os mercados do Leste e Sudeste Asiático. Os diálogos culturais na região foram fundamentais para a primeira expansão da Hallyu. Atualmente, o K-pop é o carro-chefe da Onda e se direciona a disseminação também aos mercados além-Ásia (LIE, 2012). O sucesso da música pop sul-coreana conseguiu alcançar públicos mais distantes e superar o sucesso dos K-dramas. Diferente da primeira fase, é o K-pop que introduz os K-dramas e as outras vertentes da Hallyu para audiências maiores e mais distantes. Essa expansão acontece especialmente graças ao desenvolvimento da Web 2.0, através das plataformas online e redes sociais digitais, por onde os conteúdos midiáticos do pop sul-coreano encontraram espaço para sua difusão e acesso a públicos de outros países (JIN; YOON, 2014; JUNG; LI, 2014). O desenvolvimento das tecnologias da comunicação foi peça-chave para a potencialização do mercado da Hallyu para uma lógica "global" e ainda mais lucrativa (LIE, 2012). Este contexto é essencial para compreendermos a expansão do K-pop para a esfera ocidental e o crescimento em meio a um dos mercados mais competitivos e estruturado em lógicas coloniais em seu consumo e produção de conteúdo pop: o estadunidense.

\section{ATIVISMO DE FÃ E DESOBEDIÊNCIA EPISTÊMICA: O CASO DOS ARMYS DO BTS}

A experiência do K-pop no Ocidente vem sendo mediada amplamente através dos usos das plataformas digitais, especialmente para os fãs de fora da Coreia e do Leste Asiático, que dependem delas para participarem das lógicas de fandom e consumirem os conteúdos disponibilizados pelos seus ídolos. Grupos e empresas se valem de plataformas como Youtube e VLIVE, para divulgar e comercializar o conteúdo produzido. Também é comum que os próprios artistas se utilizem das redes sociais para entrar em contato com o público (MCLAREN; JIN, 2020) e expandirem o seu potencial de alcance na indústria. Para além disso, os fãs de K-pop se apropriaram desses espaços 
para potencializar seu consumo cultural da Hallyu e, especialmente, dos seus artistas preferidos. Contudo, uma outra vertente foi desenvolvida e fomentada pelos K-poppers no ambiente online: o ativismo participativo dos fãs, que, segundo Jung (2012), se tornou um aspecto característico do universo do K-pop.

Esse ativismo dos fãs é uma lógica antiga do K-pop e potencializada pelo ambiente online. Participar de arrecadação de fundos, campanhas de reflorestamento, doações para instituições de caridade, voluntariado em situações de emergência e até mesmo protestos são parte cotidiana da vivência dos K-poppers, que tradicionalmente fazem isso em nome dos seus ídolos (JUNG, 2012). Doações de sacos de arroz decorados com fotos dos k-idols, por exemplo, se tornaram uma prática tão comum entre os fãs, que têm uma denominação própria, "Fan rice", e existem empresas na Coreia do Sul especializadas em doações de $\operatorname{arroz}^{[11]}$. Casos grandiosos de caridade também são comuns, como o caso dos fãs do B.A.P que arrecadaram fundos e construíram uma escola completa em Gana em 2018 com impacto direto mais de 700 crianças na comunidade em Aksombo Ketem ${ }^{[12]}$, ou o caso dos fãs do Seo Taiji and Boys que comemoram o $20^{\circ}$ aniversário do grupo reunindo doações para a plantar a "Seotaiji Forest" em uma área de cinco hectares na floresta de Guapiaçu, em Cachoeiras de Macacu, Rio de Janeiro ${ }^{[13]}$.

A participação dos ARMYs na arrecadação de dinheiro para apoiar o movimento Black Lives Matter (BLM) nos Estados Unidos em 2020 e a organização em favor de desbancar o evento de Donald Trump são exemplos da mesma lógica. Eles se distinguem dos demais casos, contudo, em função do seu caráter político, em favor de uma causa decolonial, que se relaciona com a própria natureza não-ocidental do fenômeno da Hallyu. A mobilização dos fãs de K-pop nos protestos de 2020 se deu em sequência ao posicionamento público dos idols sul-coreanos em favor da BLM, que tem liderado protestos pelos EUA desde a morte do segurança negro George Floyd, sob custódia policial. Após o BTS se posicionar oficialmente em 04 de junho de 2020, contra o racismo e a violência através de sua conta no Twitter, utilizando-se da hashtag \#BlackLivesMatter e fazer uma doação em conjunto com sua gravadora de 1 milhão de dólares para o referido movimento, os ARMYs criaram rapidamente outra campanha de doações com a hashtag \#MatchAMillion e o intuito de doarem em apoio à causa o mesmo valor doado pelo grupo. Em pouco mais de três dias de campanha no twitter o movimento arrecadou 1,2 milhões de dólares ${ }^{[14]}$.

Além disso, para proteger os manifestantes do BLM, os ARMYs e fã-clubes de outros grupos de K-pop se utilizaram de uma prática comum da cultura fã dos K-poppers: as fancams, como são conhecidos os vídeos feitos pelos fãs de K-pop das apresentações dos seus ídolos. A fim de derrubar um aplicativo da polícia de Dallas (EUA) que estava sendo utilizado para denunciar ativistas do movimento negro que participavam dos protestos, os K-poppers se organizaram pelo Twitter e inundaram o aplicativo com fancams, tornando impossível navegar na plataforma 
e encontrar as reais denúncias contra ativistas do BLM. Poucas horas depois do início da ação coletiva dos fãs, a polícia teve que tirar o aplicativo do ar devido ao fluxo gigantesco de vídeos enviados. Originalmente apenas um produto da cultura fã do K-pop, as fancams se tornaram um instrumento de desacato e manifestação de descontentamento com a polícia em meio ao novo levante do movimento negro nos Estados Unidos.

Então, em 20 de junho de 2020, os ARMYs coordenaram suas ações para esgotar os ingressos do comício realizado por Donald Trump em Tulsa, criando a falsa expectativa de que seria um sucesso de plateia. No entanto, o que Trump não esperava era encontrar um estádio vazio: os fãs de K-pop, em sua maioria, jovens e adolescentes, nunca tiveram a intenção de comparecer ao evento. Como fora visto até aqui, essa não foi a primeira vez que o fã-clube do BTS se engajou no intuito de cumprir um objetivo relacionado a uma causa política. No entanto, o impacto de suas ações nesse evento ameaçaram o status quo da política norte-americana, o que, portanto, causou alvoroço midiático e atraiu os olhares para os seus posicionamentos e vínculos com o consumo de K-pop. Após a ação dos K-poppers, representantes de uma pauta conservadora passou a condenar o fenômeno do K-pop, associando-os a ideia de "comunismo" e vinculando-o à China. No Brasil, situação semelhante ocorreu quando o deputado Douglas Garcia (PSL) instigou seus apoiadores via Twitter a enviarem para seu e-mail oficial dados de militantes antifascistas ${ }^{[15]}$, no que resultou numa rápida mobilização dos k-poppers brasileiros para floodarem ${ }^{[16]}$ a caixa de e-mails do deputado com fotos e fancams de seus grupos favoritos.

Do Black Lives Matter ao flop ${ }^{[17]}$ do comício do Trump, os ARMYs vem demonstrando como a desobediência epistêmica (MIGNOLO, 2008a) neste caso se reflete em um ativismo políticoidentitário altamente centrado nas discussões contra o racismo anti-negro e anti-amarelo, que dá conta de explicar a aproximação não imaginada de antemão entre os movimento dos ARMYs e o Black Lives Matter. Ser um k-popper ocidental por si só já se caracteriza como um ato de desobediência epistêmica, visto que seu consumo de imagens e sonoridades se descentralizaram de premissas culturais canônicas desse mundo ocidental, no qual reside, por exemplo, questões relacionadas à branquitude e anglofonia, tanto do ponto de vista ético quanto estético. $O$ fato de o K-pop fazer parte da lógica racial amarela e os K-poppers se posicionarem frente ao racismo anti-negro no país reverberam também a existência de uma solidariedade anti-racista histórica entre os movimentos negro (Black Panthers) e amarelo (Yellow Peril) nos Estados Unidos, apontando para um entendimento transnacional do sistema racista, parte essencial do processo decolonial. Nesta direção, o consumo de K-pop ganha uma nova dimensão política-identitária, que vai para além do entretenimento, adquirindo novas conotações dada a reflexibilidade existente no interior do fandom de K-pop. Em outras palavras, trata-se de se considerar a dimensão política das imagens e sonoridades atreladas ao K-pop e o engajamento dos seus fãs no mundo 
contemporâneo, enquanto um exemplar de estética e prática decolonial possível, dado o seu papel central no enfrentamento de desafios que vem se apresentando no presente.

\section{CONSIDERAÇÕES FINAIS}

A explosão do fenômeno da música pop, na década de 1990, foi um marco decisivo em um processo de colonialidade de matriz anglofônica, liderado pelos Estados Unidos (e secundariamente pelo Reino Unido), que atribuiu valores universais a elementos culturais específicos desses países, na esteira do processo de globalização neoliberal (ALBUQUERQUE; LYCARIÃO, 2018). Esse processo teve como uma das suas expressões mais visíveis o fenômeno da difusão global do videoclipe, capitaneado pela emissora MTV, que ajudou a tornar hegemônicas estéticas nascidas no contexto daqueles países (HOLZBACH, 2016). As últimas décadas, contudo, dão conta de uma virada importante na lógica da relação entre pop, globalização e colonialidade. A emergência do K-pop como fenômeno musical global - no contexto mais amplo da Hallyu - assinala para uma mudança expressiva a esse respeito, na medida em que elementos associados à Coreia do Sul (e ao Extremo Oriente de modo geral) começam a disputar o protagonismo da cena global do pop com a matriz anglofônica.

Não obstante o movimento do K-pop não tenha, em sua origem, um caráter essencialmente político, ele tem assumido essa característica mais recentemente, em função das tensões que caracterizam o cenário político global em um contexto de crise da hegemonia dos Estados Unidos e do aparecimento de competidores políticos e econômicos em outros países. O confronto se faz inevitável na medida em que o lema "America First!" de Donald Trump se confunde com uma agenda da supremacia branca. A aproximação do BTS com a causa do BLM, analisada nesse artigo, dá conta de um avanço expressivo no reconhecimento de uma lógica decolonial associada ao K-pop, na medida em que a união de idols e fãs de música sul-coreana com ativistas negros ressalta a distância de ambos em relação ao cânone ocidental que dominou o cenário global de maneira unipolar nas últimas décadas. 


\section{REFERÊNCIAS}

ALBUQUERQUE, A fonso; LYCARIÃO, Diógenes. Winds of change? BRICS as perspective in international media research. International Journal of communication, v. 12, p. 2873-2892, 2018.

ALBUQUERQUE, A fonso; CORTEZ, Krsytal. Cultura pop e politica na nova ordem global: lições do Extremo Oriente. In: PEREIRA, Simone; CARREIRO, Rodrigo; FERRARAZ, Rogério (orgs.). Cultura Pop. Salvador: UFBA; Brasília: Compós, 2015.

AMARAL, Adriana; SOUZA, Rosana; MONTEIRO, Camila."De Westeros no \#vemprarua à shippagem do beijo gay na TV brasileira". Ativismo de fãs: conceitos, resistências e práticas na cultura digital. Galáxia, São Paulo: PUC-SP, n. 29, p. 141-154, 2015.

BENNET, Lucy. Fan activism for social mobilization: A critical review of the literature. Transformative Works and Cultures: New York, Organization for Transformative Works, v. 10, junho, 2012, online.

CHANG, WoongJo; PARK, Shin-Eui. The fandom of Hallyu, a tribe in the digital network era: the case of ARMY of BTS. Kritika Kultura: Manila, Ateneo de Manila University, n. 32, p. 260-287, fevereiro, 2019.

FRITH, Simon. Performing rites: on the value of popular music. Harvard Univ. Pres, 1996.

GLUCK, Antje. De Westernization and Decolonization in Media Studies. Oxford Research Encyclopedia of Communication and Critical Studies (Oxford Research Encyclopedias), Oxford, UK: Oxford University Press, 2018.

HOLZBACH, Ariane. A invenção do videoclipe: a história por trás da consolidação de um gênero audiovisual. Curitiba: Editora Appris, 2016.

HUANG, Shuling. Nation-branding and transnational consumption: Japan-mania and the Korean Wave in Taiwan. Media, Culture and Society, Califórnia: SAGE Publishing, v. 33, n. 3, p. 3-18, janeiro, 2011.

HWANG, Kyung Moon. A History of Korea: An Episodic Narrative. Palgrave Macmillan. London, 2010.

JIN, Dal Yong; YOON, Kyong. The social mediascape of transnational Korean pop culture: Hallyu 2.0 as spreadable media practice. New Media \& Society, Califórnia: SAGE Publications, v. 18, n. 07, p. 1-16, outubro, 2014.

JUNG, Sookeung; LI, Hongmei. Global production, circulation and consumption of Gangnam Style. International Journal of Communication, Califórnia: University of Southern California, v. 8, p. 2790-2810, maio, 2014.

JUNG, Sun. Fan activism, cybervigilantism, and Othering mechanisms in K-pop fandom. Transformative Works and Cultures: New York, Organization for Transformative Works, v. 10, junho, 2012, online.

KEANE, Michael; FUNG, Anthony YH; MORAN, Albert. New television, globalisation, and the East Asian cultural imagination. Hong Kong: Hong Kong University Press, 2007. 
LIE, John. What is the K in K-pop? South Korean popular music, the culture industry, and national identity. Korea Observer, Seul: Yonsei University, v. 43, n. 3, p. 339-363, setembro-novembro, 2012.

MAZUR, Daniela. Um mergulho na Onda Coreana, Nostalgia e Cultura pop na série de K-drama "Reply". (Dissertação de mestrado) PPG em Comunicação. Universidade Federal Fluminense, 2018.

MAZUR, Daniela; MEIMARIDIS, Melina; ALBUQUERQUE, Afonso. Paradigmas Televisivos em Transição: A adaptação de Dramas Americanos na Coreia. Revista Latinoamericana de Ciencias de la Comunicación, v. 17, n. 31, p. 84-94, 2019

MCLAREN, Courtney; JIN, Dal Yong. "You Can't Help But Love Them”: BTS, Transcultural Fandom, and Affective Identities. Korea Journal, Pangyo: The Academy of Korean Studies, v. 60, n. 1, p. 100-127, março-junho, 2020.

MIGNOLO, Walter. A colonialidade de cabo a rabo: o hemisfério ocidental no horizonte conceitual da modernidade. In: LANDER, Edgardo (Org.). A colonialidade do saber: eurocentrismo e ciências sociais. Perspectivas latino-americanas. Buenos Aires: Clacso, p. 71-103, 2005.

Desobediência epistêmica: a opscão descolonial e o significado de identidade em politica. Cadernos de Letras da UFFDossiê: Literatura, língua e identidade, Niterói: Universidade Federal Fluminense, v. 34, p. 287-324, janeiro-junho, 2008a.

La opción decolonial: desprendimiento y apertura. Um manifiesto y un caso. Tabula Rasa, Bogotá: Universidad Colegio Mayor de Cundinamarca, n. 8, p. 243-282, janeiro-junho, 2008b.

Colonialidade: o lado mais escuro da modernidade. Revista Brasileira de Ciências Sociais, São Paulo: Associação Nacional de Pós-Graduação e Pesquisa em Ciências Sociais, v. 32, n. 94, p. 1-18, junho, 2017.

; VÁZQUEZ, Rolando. Decolonial Aesthesis: Colonial Wounds/ Decolonial Healings. Social Text, Durham: Duke University Press, julho, 2013.

MORIMOTO, Lori; CHIN, Bertha. Towards a theory of transcultural fandom. Participations: Journal of Audience \& Reception Studies, v. 10, n. 1, p. 92-108, 2013.

NYE, Joseph. Soft Power: The Means to Success in World Politics. New York, Public Affairs, 2004.

QUIJANO, Aníbal. Colonialidad del poder y clasificación social. In: CASTRO-GÓMEZ, Santiago y GROSFOGUEL, Ramón (Orgs.). El giro decolonial: reflexiones para una diversidad epistémica más allá del capitalismo global. Bogotá: siglo del Hombre Editores. Universidad Central, Instituto de Estudios Sociales Contemporáneos y Pontificia Universidad Javeriana, 2007.

SAID, Edward W. Orientalismo: o Oriente como invenção do Ocidente. Rio de Janeiro: Editora Companhia das Letras, 2007. 
SHIM, Doobo. Hybridity and the rise of Korean popular culture in Asia. Media Culture Society, Califórnia: SAGE Publishing, v. 28, n. 1, p. 25-44, janeiro, 2006.

SOARES, Thiago. Abordagens teóricas para estudos sobre cultura pop. Revista Logos, Rio de Janeiro: UERJ, v. 2, n. 24, p. 41-53, julho-dezembro, 2014.

URBANO, Krystal. Beyond Western pop lenses: o circuito das japonesidades e coreanidades pop e seus eventos culturais/musicais no Brasil, (Tese de doutorado) PPG em Comunicação. Universidade Federal Fluminense, 2018.

URBANO, Krystal; ARAUJO, Mayara; MELO, Maria Elizabeth. Orientalismo em tempos de pandemia: discursos sobre a China no jornalismo brasileiro, Revista Rizoma, v.8, n. 1, p.106-122, 2020.

WALLERSTEIN, Immanuel. O Universalismo Europeu: A retórica do poder. São Paulo: Editora Boitempo, 2007.

[1] MELO, Geovanna. Fãs de k-pop se engajam em questões políticas e sociais nas redes sociais. Correio Braziliense, 08 de julho de 2020. Disponível em: https://bityli.com/W7Qvj Acesso em: 14 de setembro de 2020.

[2] CUNHA, Gustavo. K-pop é o novo punk? Fã-clubes surpreendem com ativismo antirracista - e afirmam ter enganado Trump. O Globo, 23 de junho de 2020. Disponível em: https://bityli.com/hJtdf Acesso em: 14 de setembro de 2020.

[3] O softpower pode ser definido como a habilidade de um país em exercer influência sobre os outros através de sua capacidade de sedução, ao invés de coerção (hard power).

[4] English is no longer the default language of American pop. The Guardian, 31 de maio de 2018. Disponível em: https:// bityli.com/gR1yW Acesso em: 14 de setembro de 2020.

[5] A ideia por trás da nomenclatura é de que os fãs estariam prontos para apoiar e defender os membros do grupo. Bangtan também significa "exército" em coreano.

[6] URBIM, Emilliano. Manifestantes se apropriam da cultura pop para ir às ruas. O Globo, 11 de agosto de 2018. Disponível em: https://bityli.com/D0kHV Acesso em: 14 de setembro de 2020.

[7] BERNARDO, Kaluan. Por que direita e esquerda usam desenhos japoneses para falar de política. TAB Uol, 09 de novembro de 2019. Disponível em: https://bityli.com/ELBxV Acesso em: 14 de setembro de 2020.

[8] GROSS, Elana Lyn. BTS Is The First All-South Korean Group To Lead The Billboard Hot 100. Forbes, 31 de agosto de 2020. Disponível em: https://www.forbes.com/sites/elanagross/2020/08/31/bts-is-the-first-all-south-korean-group-tolead-the-billboard-hot-100/\#1745fde14be0 Acesso em: 14 de setembro de 2020.

[9] QUEIROGA, Louise. Coreia do Sul estima efeito econômico em R \$7,5 bi devido a 'Dynamite', novo hit do BTS. Jornal Extra, 07 de setembro de 2020. Disponível em: https://bityli.com/zVKlh Acesso em: 14 de setembro de 2020. 
[10] Seoul to further boost content, 'hallyu' in 2020 after BTS, 'Parasite' win big. Yonhap News Agency, 05 de março de 2020. Disponível em: https://en.yna.co.kr/view/AEN20200305003200315. Acesso: 14 de setembro de 2020.

[11] HEMMEKE, Katelyn. Planting Rainforests and Donating Rice: The Fascinating World of K-pop Fandom. Korea Exposé, 20 de fevereiro de 2017. Disponível em: https://www.koreaexpose.com/fascinating-world-k-pop-fandomculture/. Acesso: 14 de setembro de 2020.

[12] LIM, J. Fans Surpass Donation Goal In Order To Build A School In B.A.P's Name. Soompi, 24 de novembro de 2016. Disponível em: https:/www.soompi.com/article/918693wpp/fans-surpass-donation-goal-order-build-school-b-a-psname Acesso: 14 de setembro de 2020.

[13] KIM, Rahn. Fans name 'Seotaiji Forest' in Brazil. The Korea Times, 16 de março de 2012. Disponível em: http://www. koreatimes.co.kr/www/news/nation/2012/03/113_107088.html Acesso: 14 de setembro de 2020.

[14] BTS doa US\$ 1 milhão para o Black Lives Matter, e fãs superam valor em campanha. G1 | O Globo, 08 de junho de 2020. Disponível em: https:/g1.globo.com/pop-arte/musica/noticia/2020/06/08/bts-doa-us-1-milhao-para-o-blacklives-matter-e-fas-superam-valor-em-campanha.ghtml Acesso em: 14 de setembro de 2020.

[15] NAÍSA, Letícia. Por que fãs de kpop estão engajados nos protestos contra o racismo no mundo. TAB Uol, 10 de junho de 2020. Disponível em: https://bityli.com/R8tpC Acesso em 14 de setembro de 2020.

[16] Neologismo utilizado na internet para designar uma ação coordenada que visa a repetição do envio de algum conteúdo.

[17] Neologismo utilizado na internet para designar uma ação fracassada. 